\title{
La animación stop motion, una experiencia formativa para niñas y nî̉os
}

Sergio Osorio-Carrizosa ${ }^{1}$ y

Erik Eduardo Quiroz-López ${ }^{2}$ 


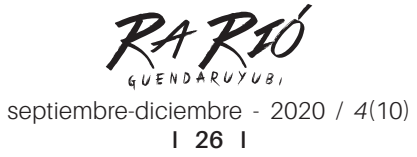

| 26 |

\section{Resumen}

El presente artículo invita a pensar en el cine de animación como un recurso que sirva de apoyo al proceso formativo de las niñas y los niños dentro del aula. Se compone de tres apartados: en el primero se comparte la experiencia del colectivo; después se examinan los talleres de animación y otras formas de trabajo pedagógico en el aula y al final se analizan las implicaciones del juego en la formación infantil.

Palabras clave: Cine de animación, niñez, juego, creatividad, imaginación.

\section{Abstract}

This paper invites you to think about animation cinema as a resource to use, that supports the educational process of girls and boys in the classroom. It is made up of three sections: in the first, the collective's experience is shared; Afterwards, animation workshops are examined as other forms of pedagogical work in the classroom, and at the end the implications of play in the formation of childhood are analyzed.

Keywords: Cinema animation, childhood, game, creativity, imagination. 


\section{Introducción}

Acercar el cine a las niñas y a los niños constituye un ejercicio significativo durante el proceso de enseñanza-aprendizaje en el ámbito escolar. Hay diferentes maneras de llevar este arte al salón de clases, una de ellas es a través de talleres de animación. En el presente artículo queremos contarte la experiencia de trabajar con niñas y niños en las escuelas públicas de Oaxaca y, más que hablar de resultados, nos gustaría compartir los retos, logros y reflexiones en torno al proceso creativo de la ninez oaxaqueña.

En un primer momento planteamos la importancia de intervenir desde el colectivo y la propuesta de proyectos participativos en contextos escolares; en segundo lugar, examinamos el trabajo que se lleva a cabo con niñas y niños en los talleres de animación que se imparten en escuelas públicas, a fin posibilitar otras maneras de la práctica pedagógica en las aulas y, por último, exponemos las implicaciones en la formación de la infancia a través del juego y el respeto a su autonomía para el desarrollo de habilidades y capacidades creativas, de colaboración y trabajo en equipo.

\footnotetext{
"¡Anímate! en tu escuela"

¿Un colectivo más en Oaxaca? ¿Vale la pena juntarse para trabajar en lo que nos gusta? Estas son algunas preguntas que nos formularon al iniciar nuestra propuesta, al final podemos decir claramente que sí, sí vale la pena trabajar en colectivo; sobre todo si se trata de la niñez, el cine y la educación. Estos son los elementos que dan vida al Colectivo Tizanduche, ${ }^{3}$ el cual se conforma por un grupo de profesionales de la educación ${ }^{4}$ interesados en difundir los derechos de las niñas y los niños, el acceso a las tecnologías de la información y comunicación (TIC) y promover la cultura.
}

${ }^{3} \mathrm{https}: / /$ www.facebook.com/Colectivo-Tizanduche-110344577116800/

${ }^{4}$ Sergio Osorio Carrizosa, Erik Eduardo Quiroz López y André Sánchez Pérez. 


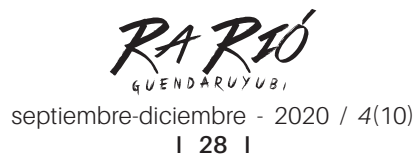

I 28 |

El objetivo del Colectivo Tizanduche es impulsar la innovación educativa en espacios escolares a través de proyectos participativos acordes con las necesidades de las comunidades donde se llevan a cabo. Por ello trabajamos en escuelas primarias del estado de Oaxaca, preferentemente ubicadas en comunidades rurales o en áreas denominadas periféricas respecto de la ciudad. Ejemplo de estos proyectos son los talleres que se realizaron sobre animación (stop motion), titulados "iAnímate! en tu escuela".

Los talleres de stop motion permiten a niños y niñas de distintos contextos formar grupos participativos para generar cortometrajes hechos por ellos/as mismos/as. Bajo esta premisa, desarrollamos una labor de una semana, tiempo necesario para llevar a cabo diferentes actividades que propician procesos creativos y formativos, cuyo resultado es un cortometraje animado.

\section{Imágenes con vida: cortos animados y la niñez oaxaqueña}

Los comienzos del cine indudablemente están relacionados con inventos y artefactos que en un principio servian para divertir a la niñez, como el taumatropo, juego que consiste en dos dibujos diferentes en ambas caras de un disco que al girar producen la ilusión de dos imágenes en una misma. Al respecto, "John A. Paris, [...] en 1825 creó el denominado taumatropo, considerado como el prototipo de los juguetes que se apoyaban en las leyes de la óptica para atraer el interés de la infancia" (Pereira, 2005, p. 35).

Con el paso del tiempo se fueron estableciendo otras opciones de hacer cine. A principios del siglo XX surgió el cine de animación, proceso en el que se sustituyeron las fotografías por la proyección de dibujos a gran velocidad.

Por eso el concepto de animación se asocia a movimiento, pero si se nos permite, podemos recurrir a la etimología de la palabra para captar toda la riqueza que posee el concepto. Animación viene del término griego "anemos" (viento, aliento) pero también del término latino "animus" (lo que da ánimo, vida). Por lo tanto, cuando utilizamos la palabra animación nos estamos refiriendo a imágenes en movimiento, pero también a imágenes con vida. Se trata de generar, conservar y presentar imágenes que producen la sensación de movimiento gracias a la rápida sucesión con la que se proyectan (Pereira, 2005, p. 24). 


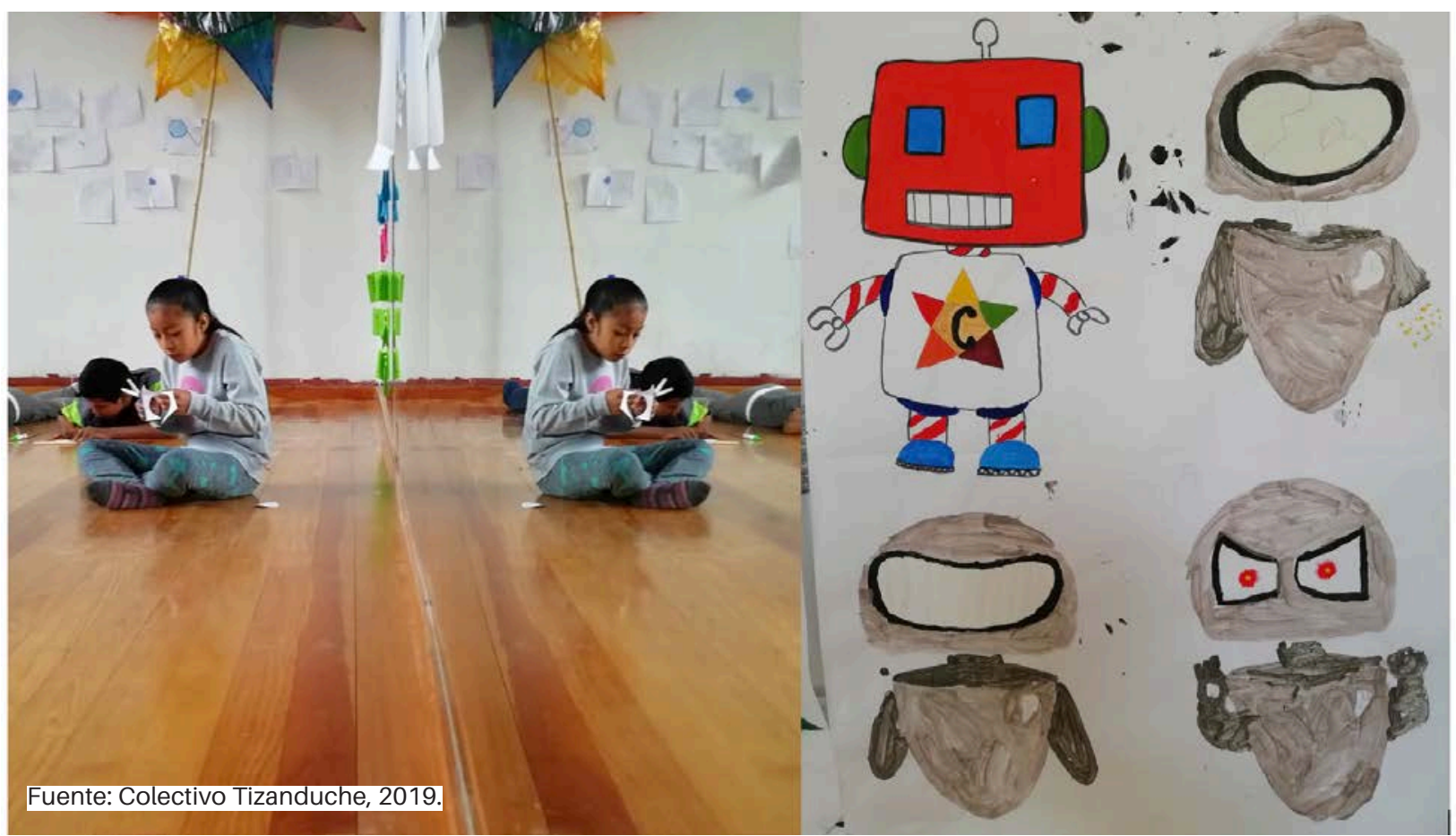

Este movimiento que crea imágenes "con vida" se filma paso a paso, por ello el término en inglés que refiere a esta técnica se llama stop motion, que literalmente alude a detener el movimiento para grabar cuadro por cuadro; luego se le da movimiento y vida a una gran historia.

Es sorprendente observar a las niñas y los niños participando en el proceso creativo y adentrarse en el maravilloso mundo del stop motion. Esta técnica del cine es la que más se ha acercado al público infantil y éste, a su vez, la ha aceptado con gran emoción y asombro para dar vida a sus propias historias.

La animación es solo un pretexto para que niñas y niños desarrollen su creatividad, conozcan algo diferente que les impresione, que les llame la atención y den rienda suelta a su imaginación. El stop motion es una herramienta para activar la mente y expresar ficciones que aún no han sido contadas o recreadas en un cortometraje.

El cine de animación es muy amplio, ya que existen diferentes técnicas. En el transcurso de nuestros talleres utilizamos tres técnicas en particular: cut out o animación con recortes, ${ }^{5}$ pixilación ${ }^{6}$ y claymation o plastilina. ${ }^{7}$

\footnotetext{
${ }^{5}$ Cut out o animación con recortes se logra dibujando y recortando los objetos y los personajes, posteriormente se colocan en un escenario y se filma cada paso.

${ }^{6}$ En la pixilación nuestro objetivo a grabar es el cuerpo humano, los actores son usados como objetos y de igual manera se les graba movimiento por movimiento.

${ }^{7}$ Claymation o plastilina es la más utilizada en la grabación de cortometrajes y largometrajes, para su realización no solo se usa plastilina, sino todos aquellos materiales maleables (barro, arena, masa, etcétera).
} 


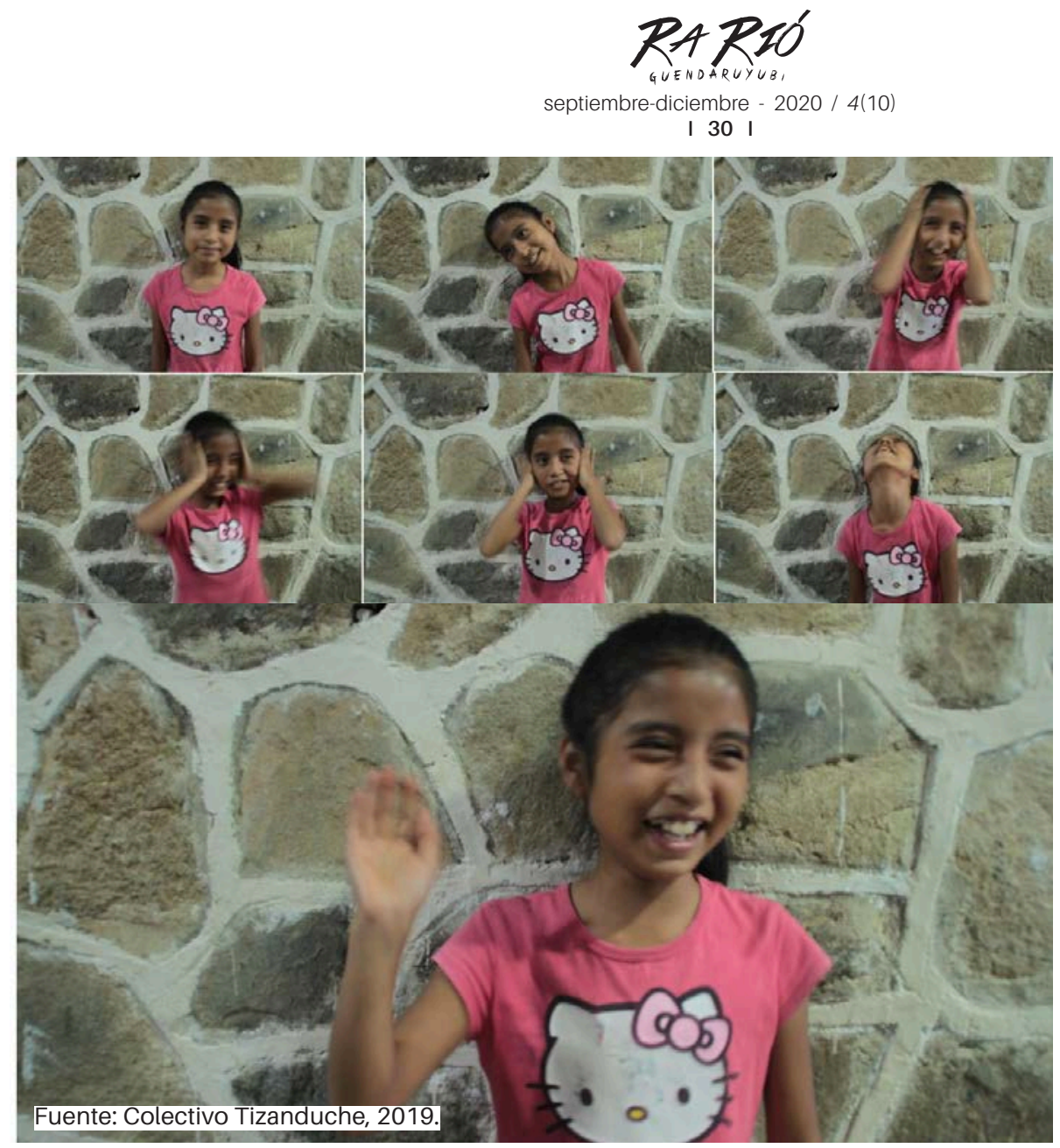

Estas técnicas son las más utilizadas dentro del stop motion, ya que todas cumplen con el elemento primordial: grabar paso por paso; es decir, "el principio mismo en el que se basa la animación: la sensación de movimiento a partir de dibujos, figuras recortadas, marionetas o muñecos de plastilina o de cualquier otro material" (Pereira, 2005, p. 25).

\section{El juego y la autonomía como motor creativo}

Emprender un proyecto de animación con niñas y niños requiere ejecutarse organizadamente y sin prisas, es necesario trabajar con distintas herramientas que hagan divertida e interesante la actividad. Además de implementar las técnicas antes mencionadas, el juego es el mejor recurso para efectuar todas las tareas del taller, porque cumple una función esencial en la adquisición de conocimientos y desarrollo de habilidades en la niñez. Así también, a través de esta actividad, los/as niños/as aprenden a relacionarse con los otros y a trabajar en equipo, además de que fortalecen su capacidad creativa y organizativa, para posteriormente poner en práctica todo lo aprendido. De ahí que el juego nos muestra "la importancia capital que tiene en el desarrollo total del niño, en la conformación de una personalidad sana y equilibrada y en el valor de las relaciones sociales que estructura" (Zapata, 1995, p. 32). 


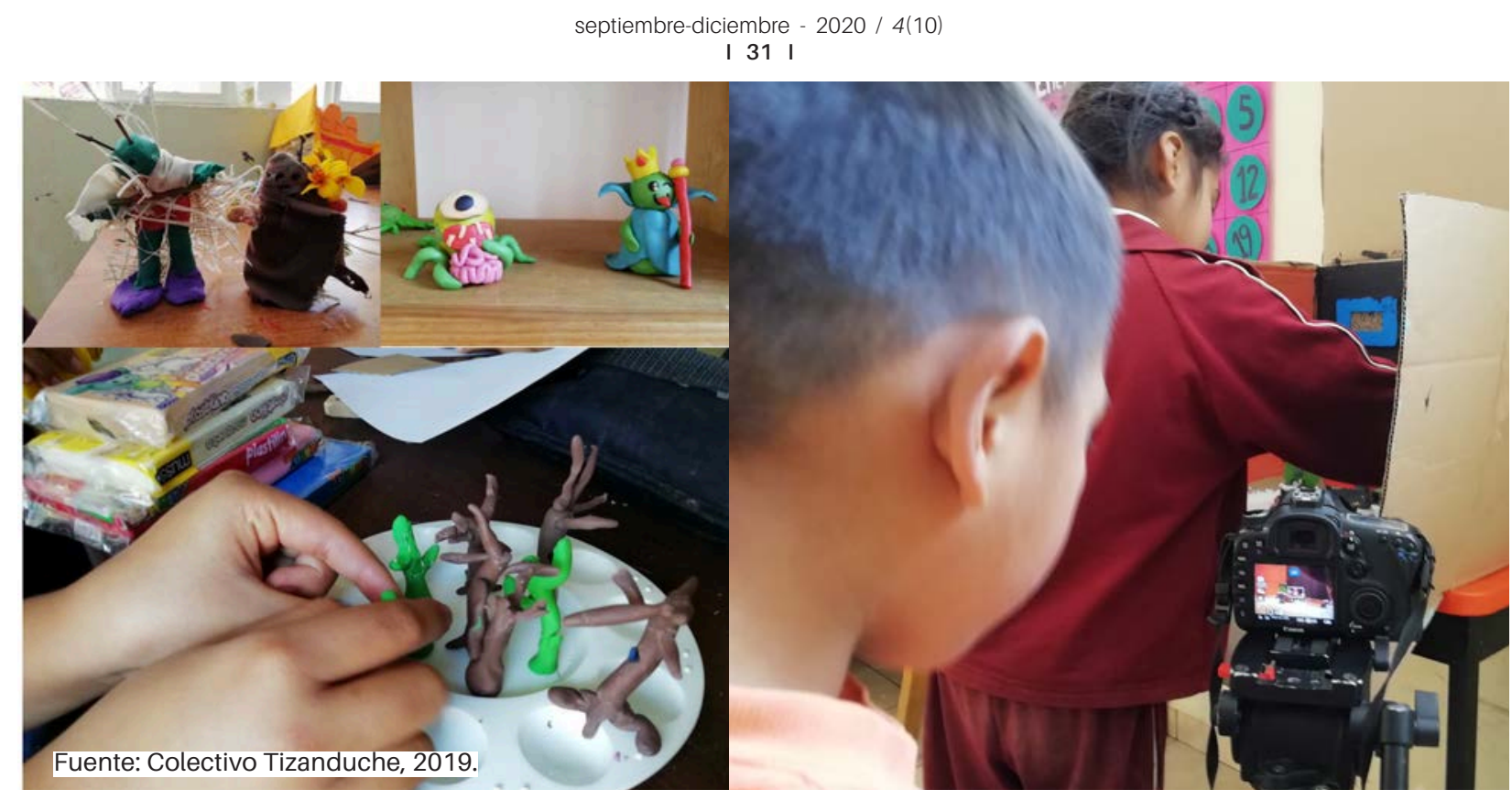

Lo anterior cobra sentido cuando en los talleres de animación se elabora el taumatropo, cuando se construyen los escenarios con materiales reciclados, cuando se crean personajes elaborados con plastilina y objetos locales tales como hojas de papel, ramas secas de los árboles, piedras, tierra, arena, etcétera. Todo ello se vuelve un pretexto para cultivar en el niño y la niña habilidades y capacidades creativas, formas colaborativas y cooperativas de organización pero, sobre todo, respeto a su autonomía.

Al respecto, Paulo Freire apunta que un saber imprescindible en la práctica educativa es "el respeto debido a la autonomía del ser del educando" (Freire, 2004, p. 58), lo cual se toma en cuenta en cada uno de los pasos del proceso de creación de un cortometraje, pues son niñas y niños quienes eligen e inventan las historias, personajes y materiales; se respeta su gusto estético, sus inquietudes y su narrativa.

Las niñas y los niños se organizan y se ponen de acuerdo para trabajar y colaborar, para llevar a cabo aquello que imaginaron entre todos y todas a fin de materializarlo en un cortometraje animado. Tanto sus historias como sus personajes son creaciones que imaginan en conjunto.

La forma de trabajo es en colectivo y de manera cooperativa, cada uno/a de las y los participantes sabe que cuando se labora en equipo todas y todos aportan algo a la historia que quieren contar, buscan siempre opciones para organizarse y trabajar que los lleven a cumplir los objetivos propuestos. Saben que si una persona no trabaja, no podrán avanzar de manera conjunta; por eso, ellos/as mismos/as tienen que apoyarse e invitar al otro u otra a que colabore. 


\section{RAR20́}

septiembre-diciembre - $2020 / 4(10)$

$$
\text { I } 32 \text { I }
$$

En los proyectos de animación que se llevan a cabo con niñas y niños es necesaria la toma de acuerdos que contribuyan al desarrollo de las actividades. De ahí que resulte importante incentivar la autonomía, que como saber de la práctica educativa implica "la capacidad de diálogo verdadera, en la cual los sujetos dialógicos aprenden y crecen en la diferencia, sobre todo en su respeto" (Freire, 2004, p. 59). Hacer un cortometraje de stop motion requiere de muchos pasos a seguir y demanda tiempo y organización, cada uno/a de las y los participantes desempeña un papel esencial en el desarrollo. A pesar de la complejidad del cine de animación, sabemos que niñas y niños poseen una gran imaginación, trabajan en equipo y cooperan entre todas y todos: dialogan, escuchan, opinan, eligen, votan, organizadamente. Como muestra del trabajo que han hecho, te compartimos un enlace donde podrás ver distintos cortometrajes animados realizados entre julio y septiembre de $2019 .{ }^{8}$

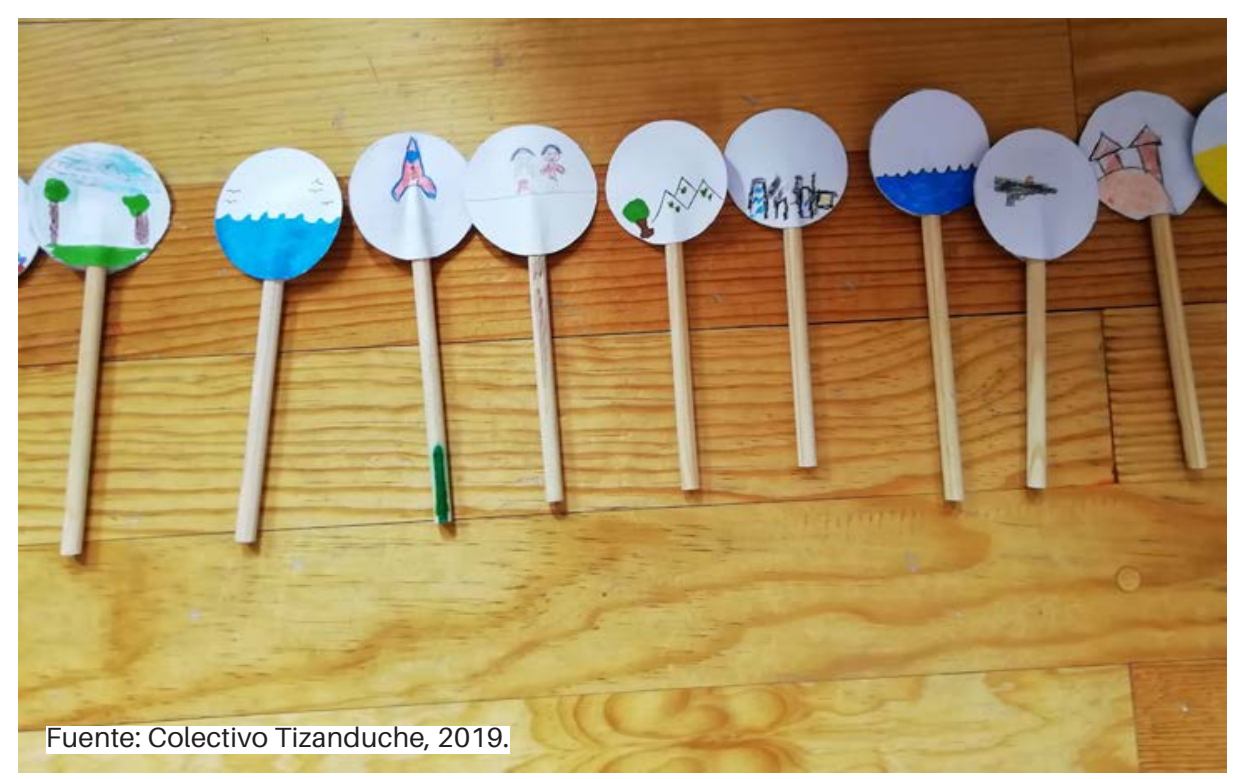

${ }^{8}$ Disponible en http://ccemx.org/animate/ 


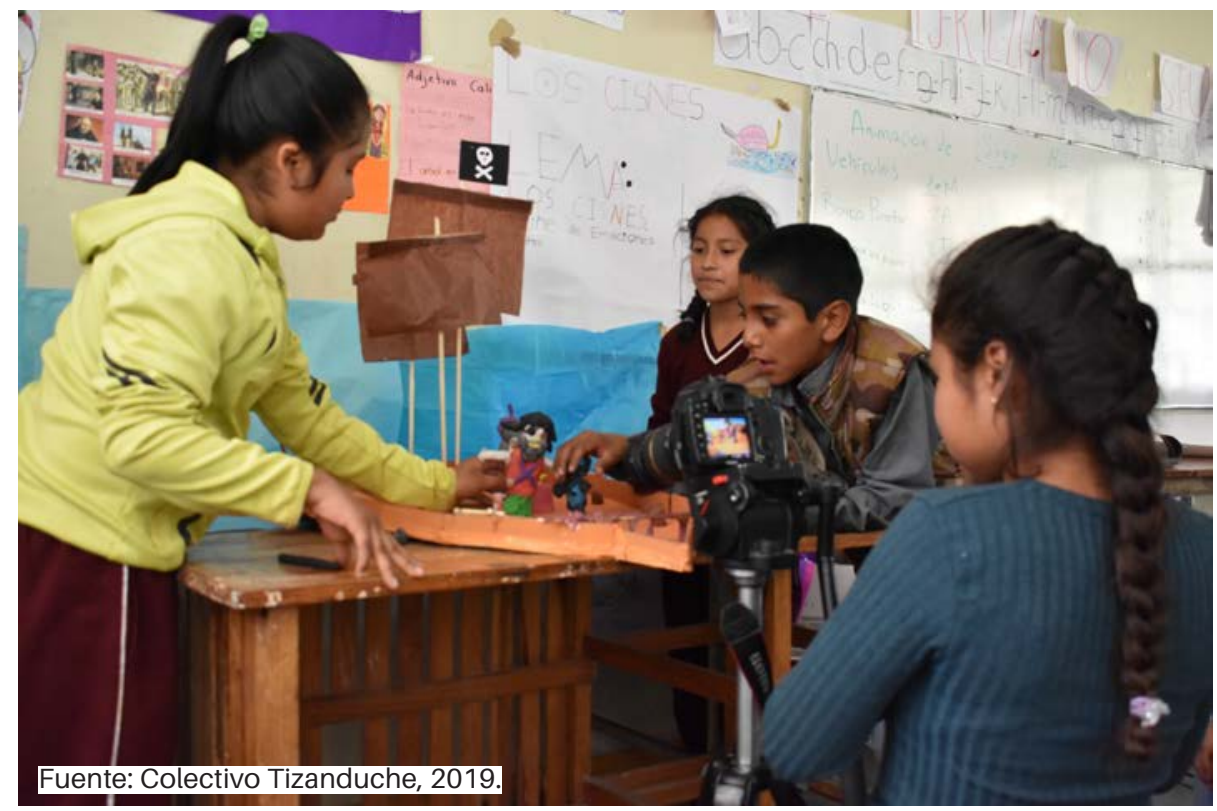

\section{Conclusión}

A manera de conclusión, y con base en la experiencia del Colectivo Tizanduche, afirmamos que es necesario seguir acercando el cine a las niñas y los niños, en sus diferentes manifestaciones, desde la proyección de películas hasta la implementación de talleres que les brinden las herramientas para crear sus propias animaciones. Tenemos presente la importancia y el valor que tiene el cine en la formación de la niñez, ya que en nuestros tiempos se vive en un mundo completamente audiovisual, creemos que este recurso puede ser uno de los mejores medios de expresión para que las voces de niñas y niños sean escuchadas.

\section{Referencias}

Freire, P. (2004). Pedagogía de la autonomía. España: Siglo XXI editores.

Pereira, C. (2005). Los valores del cine de animación. Propuestas pedagógicas para padres y educadores. Barcelona: PPU S. A. https://consumoetico.webs.uvigo.es/textos/textos/1cine. pdf

Zapata, O. (1995). Aprender jugando en la escuela primaria. Didáctica de la psicología genética. México: Editorial Pax México. 